\title{
In Situ TEM Characterization of Redox Processes in Ceria-Zirconia
}

\author{
Ruigang Wang, ${ }^{* * *}$ Peter A. Crozier, ${ }^{* *}$ Renu Sharma, ${ }^{* *}$ and James B. Adams ${ }^{* * * *}$ \\ *Science and Engineering of Materials Program, Arizona State University, Tempe, AZ 85287-1704 \\ ${ }^{* *}$ Center for Solid State Science, Arizona State University, Tempe, AZ 85287-1704 \\ ${ }^{* * *}$ Chemical and Materials Engineering, Arizona State University, Tempe, AZ 85277-6006
}

The ability of cerium oxides to reversibly form mixed +3 and +4 valence oxides $\left(\mathrm{CeO}_{2}\right.$ and $\left.\mathrm{Ce}_{2} \mathrm{O}_{3}\right)$ leads to excellent oxygen storage capacity (OSC). Oxygen vacancy ordering may inhibit the reversible nature of the redox process and it has been reported that the doping with zirconia not only improves the life of the redox cycles but also lowers the reduction temperature. Therefore nanoscale ceria-zirconia particles have been widely used in automobile three-way catalysts to adjust the local oxygen environment in order to remove the unwanted gases from exhaust to reduce pollution. However, the complex nature of $\mathrm{CeO}_{2}-\mathrm{ZrO}_{2}$ solid solution leads to two types of heterogeneity especially at the nanometer level: chemical composition heterogeneity ( $\mathrm{x}$ in $\mathrm{Ce}_{\mathrm{x}} \mathrm{Zr}_{1-\mathrm{x}} \mathrm{O}_{2}$ ) and crystallographic heterogeneity (cubic and/or tetragonal etc.). Consequently structural and chemical information at the nanometer level is critical to understand and optimize redox performance in these materials. Furthermore, the redox behavior of $\mathrm{Ce}$ is difficult to observe, as partially reduced cerium oxide is unstable at low temperatures and/or in high oxygen partial pressure. For this reason, we have undertaken a detailed in situ TEM study of the dynamic nanostructural and nanochemical changes that take place in ceria and ceria zirconia during redox cycles [1].

High surface area samples of $50 \% \mathrm{CeO}_{2} 50 \% \mathrm{ZrO}_{2}$ samples were prepared by the spray freezing method. Samples were calcined at $500^{\circ} \mathrm{C}$ for $5 \mathrm{~h}$ in air and then subjected to one redox cycle (reduced in $\mathrm{H}_{2}$ at $1000^{\circ} \mathrm{C}$ for $2.75 \mathrm{hs}$ and subsequently re-oxidized in air). In situ nanocharacterization was performed in an environmental scanning transmission electron microscopy (ESTEM) Tecnai F20, operated at $200 \mathrm{KV}$ and equipped with a Gatan imaging filter (GIF) and annular dark-field detector. Ceria-zirconia powder was dispersed over Pt grids and loaded into the microscope in a Gatan heating holder. The samples were heated progressively up to reduction temperature in 1.5 Torr of dry $\mathrm{H}_{2}$. Time and temperature resolved high resolution electron microscopy (HREM) images and energy-loss spectra were recorded to follow the structural and chemical changes during the reduction in $\mathrm{H}_{2}$. The chemical profile of individual nanocrystallites was obtained by using a sub-nanometer beam in STEM mode and recording electron energy-loss spectra (EELS) every 0.5 or $1 \mathrm{~nm}$ (EELS line scans) from individual particles. The EELS line scans were processed to determine the variation in $\mathrm{Ce} / \mathrm{Zr}$ atomic ratio between different nanoscale grains and within individual nanoparticles.

Figure 1 shows the Z-contrast STEM image (a) and compositional variation (b) across two individual nanoparticles. XRD (Figure 1 (b) inserted) suggested a "homogeneous" solid solution, but EELS nanoanalysis revealed 10 15\% composition variation between individual grains and within some grains (not shown). Figure 2 shows in situ HREM image at $586^{\circ} \mathrm{C}$ in 1.5 Torr of dry $\mathrm{H}_{2}$ and associated $\mathrm{Ce} \mathrm{M}_{4,5}$ (white-lines) spectra from a $\mathrm{CeO}_{2}-\mathrm{ZrO}_{2}$ nanoparticle during the redox cycle: before reduction at $486^{\circ} \mathrm{C}, 586^{\circ} \mathrm{C}$ (reduced) and $472^{\circ} \mathrm{C}$ after re-oxidation. At $586^{\circ} \mathrm{C}$, local superstructure (oxygen vacancy ordering or intermediate phase) was observed in reduced nanoparticles. Significant changes in the relative intensity ratio of the $\mathrm{Ce}$ white-lines were not observed until $586^{\circ} \mathrm{C}$. At this temperature, the $\mathrm{M}_{5} / \mathrm{M}_{4}$ intensity ratio changed from $0.65\left(486^{0} \mathrm{C}\right)$ to 
$\sim 0.73\left(586^{\circ} \mathrm{C}\right)$ indicating that a fraction of the $\mathrm{Ce}^{+4}$ species transformed to the $\mathrm{Ce}^{+3}$ oxidation state. When the sample was cooled to $472^{\circ} \mathrm{C}$ the white-line ratio confirmed the ceria re-oxidation of $\mathrm{Ce}^{+3}$ to $\mathrm{Ce}^{+4}$. We will describe the correlation between the local structure, chemical composition and redox behavior of individual nanograins as determine by our in situ experiments.

\section{References}

[1] Sharma R. et al., Phil. Mag. 84 (2004) 2731

[2] The support from the National Science Foundation (NSF-CTS-0306688) and the use of TEM at the John M.Cowley Center for High Resolution Microscopy at Arizona State University are gratefully acknowledged.
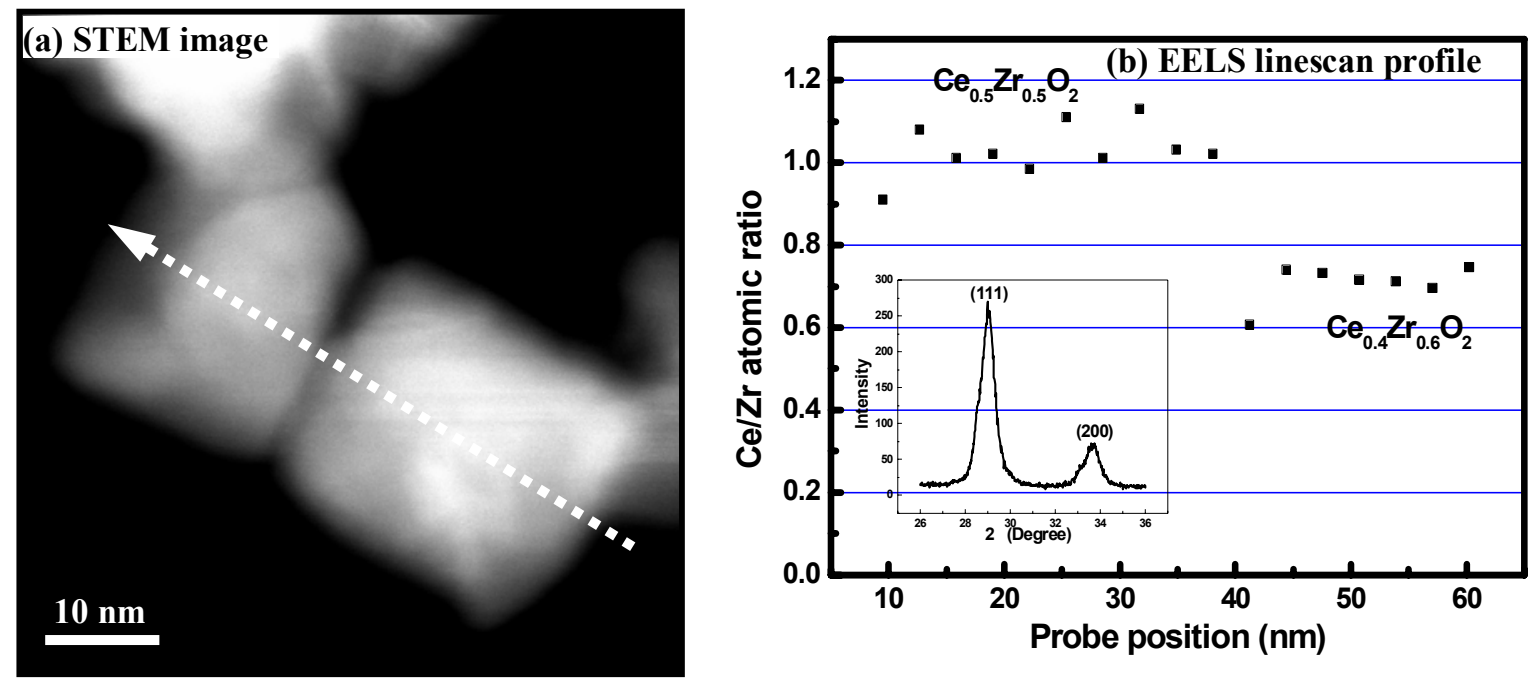

Fig. 1. STEM image (a), chemical profile (b) from EELS linescan and XRD pattern (inserted in (b)) of two ceria-zirconia nanoparticles
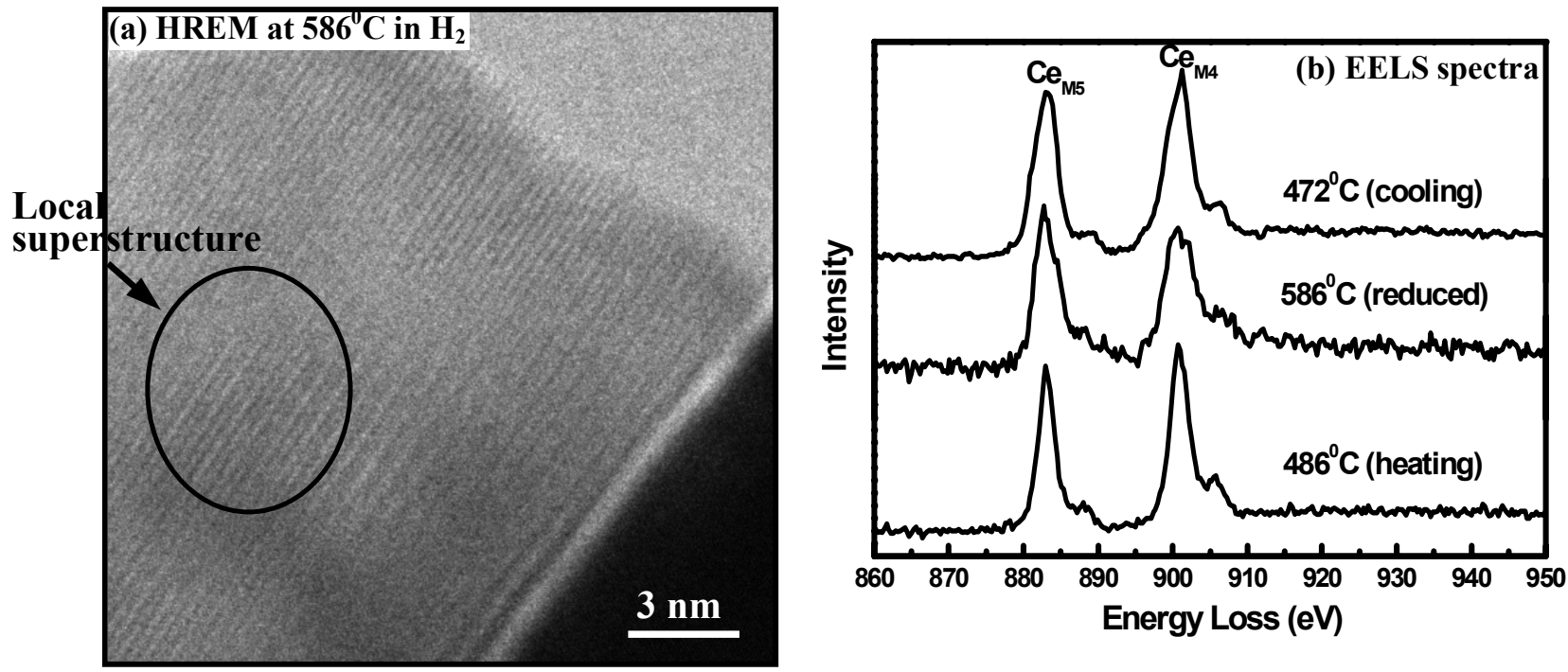

Fig. 2. HREM image recorded at $586^{\circ} \mathrm{C}$ showing doubling of $<111>$ spacing, due to oxygen vacancy ordering in 1.5 Torr of $\mathrm{H}_{2}$ (a) and associated EELS spectra (b) during redox process of a $\mathrm{Ce}_{0.5} \mathrm{Zr}_{0.5} \mathrm{O}_{2}$ naonoparticle 